\title{
Study of the Relationship between Anti-Peroxidase Antibody and Miscarriage, Preterm Labor and IUGR in Egyptian Pregnant Women
}

\author{
Ahmed S. El-Halwagy \\ Obstetrics and Gynecology Faculty of Medicine Tanta University, Tanta, Egypt \\ Email: halwagy22@yahoo.com
}

How to cite this paper: El-Halwagy, A.S. (2017) Study of the Relationship between Anti-Peroxidase Antibody and Miscarriage, Preterm Labor and IUGR in Egyptian Pregnant Women. Open Journal of Obstetrics and Gynecology, 7, 494-502.

https://doi.org/10.4236/ojog.2017.75051

Received: December 14, 2016

Accepted: May 14, 2017

Published: May 17, 2017

Copyright $\odot 2017$ by author and Scientific Research Publishing Inc. This work is licensed under the Creative Commons Attribution International License (CC BY 4.0).

http://creativecommons.org/licenses/by/4.0/

(c) (i) Open Access

\begin{abstract}
Background: This research studied the relationship between anti-peroxidase anti-body in euthyroid pregnant female and miscarriage, preterm labor and IUGR in Egyptian patients. Patients and Methods: This prospective study was carried on patients who attended to the Obstetrics and Gynecology department of Tanta University Hospital for routine antenatal care from January 2016 to November 2016. 80 women enrolled in the study and were divided into four groups, 20 cases for each group, a control group, recurrent unexplained abortion group, preterm labor group and IUGR group. A Thyroperoxidase (TPO) antibody was measured in all cases. Results \& Discussion: The eighty patients were randomly enrolled into 4 groups, 20 patients in each group. Their age ranged from 20 to 35 years and BMI ranged from 18 to 35 . The percentage of +ve TPO Ab of the control group was $5 \%$ and of the recurrent abortion group was $20 \%$ and of the preterm labor group was $15 \%$ and of the IUGR group it was $5 \%$. (P value 0.026 ) indicating statistically significant correlation between TPO Ab and recurrent unexplained abortion and preterm labor. Conclusion: The presence of (TPO) antibodies could be correlated to recurrent unexplained abortion and preterm labor. More studies are required to determine whether an intervention is needed to treat thyroid autoantibody positivity during pregnancy.
\end{abstract}

\section{Keywords}

Thyroid Autoimmunity, Recurrent Abortion, Pretem Labor, IUGR

\section{Introduction}

Abortion, the pregnancy wastage before 20 weeks of gestation, affects up to $20 \%$ 
of pregnant women, making it the commonest complication of pregnancy [1]. Preterm labor, premature delivery of a baby after 24 and before 37 completed weeks of gestation, its incidence is $6 \%-10 \%$ of pregnancies [2]. Up to $85 \%$ of neonatal deaths are due to preterm labor (especially if delivery is before 28 weeks). Of those who survive, around $10 \%$ have long term disability. The cost of preterm birth is $£ 93$ million a year in the United Kingdom. This includes healthcare costs (including neonatal care), education, and costs to the parents [3].

Mounting evidence that autoimmune thyroid disorders are important risk factor for abortion and premature labor [4]. Data about association of thyroid autoimmunity and intra-uterine growth restriction (IUGR) are limited to some reports about Graves' disease in pregnancy that was associated with IUGR [5] [6]. The presence of thyroid autoantibodies is somewhat common in females of reproductive years. In a random sample of women, the prevalence of autoimmune tyroid antibodies ranges from $6 \%$ to $20 \%$ [7], being even higher in women with a history of habitualabortion, at around $17 \%-33 \%$ [8] [9] [10], and subfertile women, at around $10 \%-31 \%$ [11]. In the developed countries, thyroid autoimmune disorders are the main etiology of hypothyroidism, which is a risk factor for poor pregnancy outcomes. Even in females with euthyroid function, studies have reported a correlation between the presence of thyroid autoantibodies, specially thyroid peroxidase (TPO) antibodies and pregnancy complications, including abortion, premature labor, and adverse neuro-developmental squeal in children [12]. Unknown exact mechanisms of associations, though two theories have been proposed. The first one is the presence of thyroid autoantibodies in females with euthyroid function could be associated with a minimal deficiency in the availability of thyroid hormones (even within the normal reference range) or incapability of the thyroid gland to sufficiently rise to the increased demand for thyroid hormones needed in pregnancy [13]. The second one, thyroid autoantibodies might reflects an underlying generalized autoimmune condition with a direct adverse effect on placental or fetal development [13].

\section{Patients and Methods}

This prospective study was carried on patients who attended to the Obstetrics and Gynecology department of Tanta University Hospital for routine antenatal care. A written consent was taken from each patient.

The research was done in a period of 11 months from January 2016 to November 2016. After approval of the study by the Local Ethical Committee and obtaining patients' written fully informed consent; 80 women within the reproductive age enrolled in the study. Patients were divided according to their clinical presentation into four groups, 20 cases for each group as following:

\section{- Study group 1: Control group}

They will act as control group including normal pregnancy without any complication, normal investigation and no risk factors. 


\section{- Study group 2: Recurrent abortion}

Included cases with recurrent unexplained abortion either in the first or second trimester without definite cause. The following factors must be within normal as obstetric and family history, age, exposure to toxins, $\mathrm{CBC}$, Antiphospholipid AB, Lupus Anti-coagulant, RBS, U/S and Hystro-salpingogram.

\section{- Study group 3: Preterm labour}

Cases with active preterm labor which is infant born before 37 weeks and after age of viability in which there is no fetal causes as congenital anomalies or maternal causes as infection, DM, Hypertension, placenta previa or abrubtio placenta. The following investigation was done as $\mathrm{CBC}$ and RBS and U/S.

\section{- Study group 4: Intrauterine growth retardation (IUGR)}

IUGR means birth weight less than 10th percentile for its gestational age in which there is also no fetal or maternal causes.

\section{Inclusion criteria:}

- Age: no selected age.

- Pregnant female at routine antenatal care.

- Singleton pregnancy.

\section{Exclusion criteria:}

- Any risk factor of pregnancy as cardiac, diabetic or hypertensive patients.

- History of thyroid disorders or thyroid medications.

All patients were assessed by history taking, clinical examinations and were investigated by routine investigation to check for general condition. And Special laboratory investigation:

- Anti-Thyroid Peroxidase Anti-body in serum. (The test is an Immunometric Enzyme Immunoassay for the quantitative determination of antibodies against thyroid peroxidase (TPO), (it is a product of CALBIOTECH A life science Company).

- TSH is done for all patients.

Statistical Data Analysis:

Statistical presentation and analysis of the present study was conducted, using the mean, standard deviation and chi-square test by SPSS V.20.

1) Mean value $(X)$ :

The sum of all observations divided by the number of observation:

$$
(X)=\frac{\sum x}{n}
$$

where $\sum=$ sum \& $n=$ number of observations.

\section{2) Standard Deviation [SD]:}

It measures the degree of scatter of individual varieties around their mean:

$$
S D=\sqrt{\frac{\sum|x-x|^{-2}}{n-1}}
$$

\section{3) Analysis of variance [ANOVA] tests:}

According to the computer program SPSS for Windows. ANOVA test was used for comparison among different times in the same group in quantitative data. 


\section{4) Chi-square}

The hypothesis that the row and column variables are independent, without indicating strength or direction of the relationship.

Pearson chi-square and likelihood-ratio chi-square. Fisher's exact test and Yates' corrected chi-square are computed for $2 \times 2$ tables.

Chi-square test:

For comparison between two groups as regards qualitative data.

$$
x^{2}=\sum \frac{(o-E)^{2}}{E}
$$

Where: $\sum$ = Summation; $O=$ Observed value.

$$
E=\text { Expected value }=\frac{\text { vertical total } \times \text { horizontal total }}{\text { grand total }}
$$

\section{Results}

On comparing age (Table 1 ) between the different study groups no statistically significant difference was found $(P=0.064)$.

On comparing BMI (Figure 1 ) between the different study groups no statistically significant difference was found $(P=0.583)$.

Table 1. Comparison of the mean age between the different study groups.

\begin{tabular}{ccccc}
\hline Age & Control & Abortion & Preterm & IUGR \\
\hline Range & $20-35$ & $20-34$ & $20-28$ & $20-35$ \\
Mean \pm SD & $25.6 \pm 3.44$ & $26.95 \pm 4.86$ & $23.75 \pm 2.73$ & $26.55 \pm 4.65$ \\
F test & & \multicolumn{2}{c}{2.519} & \\
P value & & \multicolumn{2}{c}{0.064} \\
\hline
\end{tabular}

Interval Plot of C1; C2; ... $95 \% \mathrm{Cl}$ for the Mean

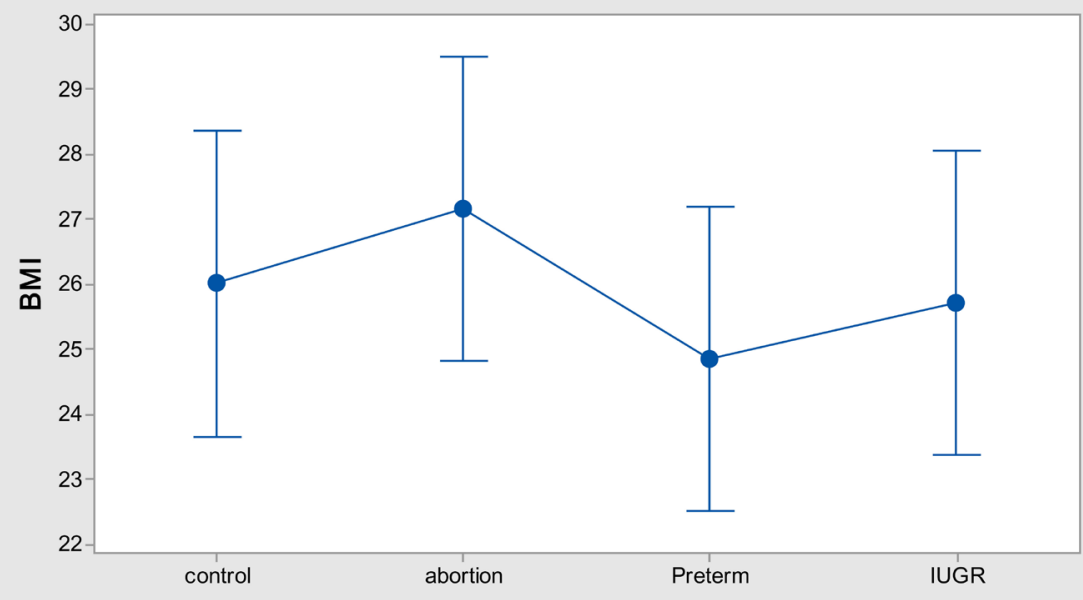

The pooled standard deviation was used to calculate the intervals.

Figure 1. Comparison of the BMI between the different study groups using One way ANOVA test. 
On comparing the study groups regarding the rate of $+\mathrm{ve}$ Thyroperoxidase antibodies (Table 2 and Figure 2). There is a statistically significant difference. $(P=0.026)$

On comparing the study groups regarding the percentage of subclinical hypothyroidism (Table 3 ) there is no statistically significant difference $(P=0.551)$.

There is a statistically significant association between subclinical hypothyroidism and +ve TPO antibody (Table 4).

\section{Discussion}

The prevalence of thyroid autoimmunity in our study was (20\%) in pregnant

Table 2. The percentage of TPOAb +ve and TPOAb -ve in different study groups.

\begin{tabular}{|c|c|c|c|c|c|c|}
\hline \multicolumn{2}{|c|}{ TPO } & Control & Abortion & Preterm & IUGR & Total \\
\hline \multirow[b]{2}{*}{$+\mathrm{ve}$} & $\mathbf{N}$ & 1 & 4 & 3 & 1 & 9 \\
\hline & $\%$ & $5.0 \%$ & $20.0 \%$ & $15.0 \%$ & $5.0 \%$ & $11.3 \%$ \\
\hline \multirow{2}{*}{-ve } & $\mathbf{N}$ & 19 & 16 & 17 & 19 & 71 \\
\hline & $\%$ & $95.0 \%$ & $80.0 \%$ & $85.0 \%$ & $95.0 \%$ & $88.8 \%$ \\
\hline \multirow{2}{*}{ Chi-square } & $X^{2}$ & & & 9.237 & & \\
\hline & $P$-value & & & $0.026^{*}$ & & \\
\hline
\end{tabular}

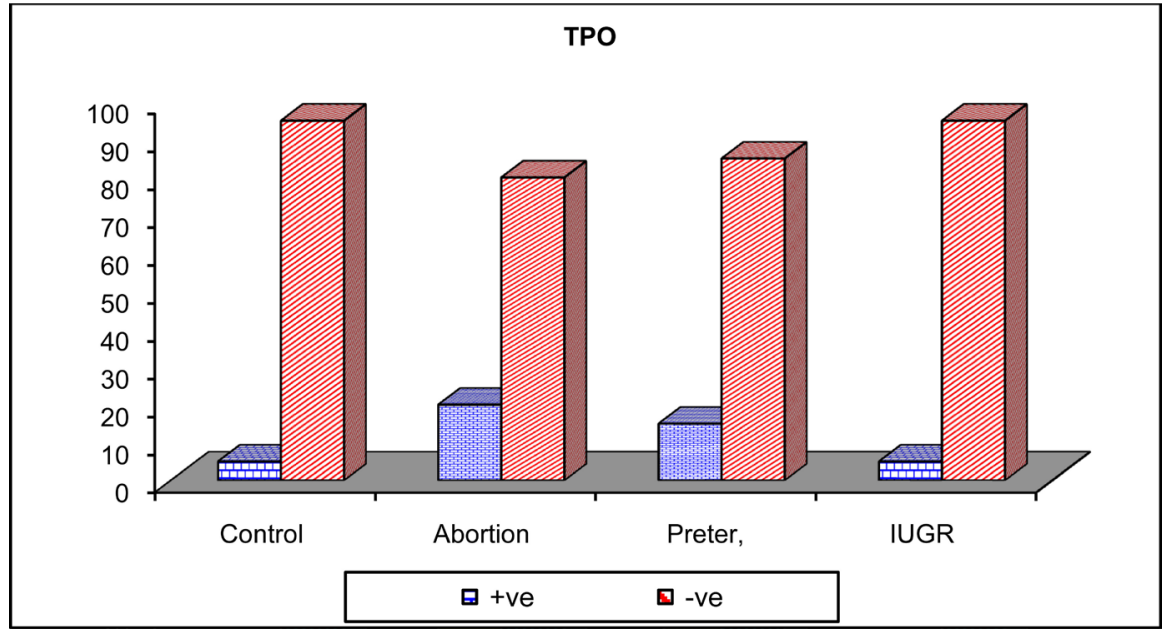

Figure 2. The percentage of TPOAb +ve and TPOAb -ve in different study groups.

Table 3. The percentage of subclinical hypothyroidism in different study groups.

\begin{tabular}{ccccccc}
\hline \multirow{2}{*}{ TSH } & & Control & Abortion & Preterm & IUGR & Total \\
\hline \multirow{2}{*}{ Normal } & $N$ & 19 & 18 & 19 & 20 & 76 \\
& $\%$ & $95.0 \%$ & $90.0 \%$ & $95.0 \%$ & $100.0 \%$ & $95.0 \%$ \\
Abnormal & $N$ & 1 & 2 & 1 & 0 & 4 \\
& $\%$ & $5.0 \%$ & $10.0 \%$ & $5.0 \%$ & $0 \%$ & $5.0 \%$ \\
& $X^{2}$ & & & 2.105 & & \\
Chi-square & $P$-value & & & 0.551 & & \\
& & & & &
\end{tabular}


Table 4. The incidence of subclinical hypothyroidism in TPOAb+ and TPOAb-groups.

\begin{tabular}{|c|c|c|c|c|}
\hline & & \multicolumn{2}{|c|}{ TSH type } & \multirow{2}{*}{ Total } \\
\hline & & Normal & Abnormal & \\
\hline \multirow{4}{*}{ TPO } & $N$ & 6 & 3 & 9 \\
\hline & $\%$ & $7.9 \%$ & $75 \%$ & $11.3 \%$ \\
\hline & $N$ & 70 & 1 & 71 \\
\hline & $\%$ & $92.1 \%$ & $25 \%$ & $88.8 \%$ \\
\hline \multirow{2}{*}{ Chi-square } & $X^{2}$ & & 17.142 & \\
\hline & $P$-value & & $0.001^{*}$ & \\
\hline
\end{tabular}

women with recurrent abortion, (15\%) in women with preterm labor and (5\%) in women with intrauterine growth retardation (IUGR) while it was (5\%) in the healthy control group $(P=0.026)$.

This study mostly is the first one in Egypt to investigate the association of thyroid autoimmunity and adverse pregnancy events.

The latest Guidelines of American Thyroid Association stated that there is insufficient evidence during pregnancy to recommend for or to recommend against screening or treating all pregnant females for thyroid autoimmunity although many studies have been done about the adverse effect of thyroid autoimmune antibodies on pregnancy [14].

\section{- Association of thyroid autoimmunity and abortion}

The current study showed a significantly higher prevalence of the rate of TPO +ve cases in abortion group (20\%) compared to controls (5\%).

A meta-analysis by Prummel et al. 2004 showed that TPOAb+ve were associated with a two folds-increased risk of abortion as shown in this study [13].

Stagnaro-Green et al. [15] reported a statistically significant doubling in the abortion rate in American euthyroid women in the first trimester of pregnancy who were thyroid antibody positive [15].

In Belgium Glinoer and colleagues in 1991 [16] reported findings of a prospective study of 120 female with normal thyroid functions with mild thyroid abnormalities (nodules, goiter or thyroid antibody positivity) and 630 euthyroidcontrols. Women with thyroid autoimmunity were found to have a dramatic increase in spontaneous abortion when contrasted to controls $(13.3 \%$ versus $3.3 \%, P<0.001)[16]$.

Lejeune et al. in 1993 [17] evaluated 363 women in the first trimester of their pregnancy, 21 of whom spontaneously miscarried. In this cohort, $22 \%$ with positive thyroid antibodies aborted compared to $5 \%$ with antibody negative ( $p<$ 0.005). The abortions associated with thyroid autoimmunity took place early, within the first trimester of pregnancy [17].

\section{- Association of thyroid autoimmunity and preterm delivery}

The current study showed a significantly higher prevalence of the rate of TPO +ve cases in preterm birth subjects group (15\%) compared to controls (5\%).

Six studies [18]-[23] including a total of 12,566 women evaluated the associa- 
tion between thyroid autoantibodies and premature labor. All were cohort studies and had low risk of bias for selection and outcome assessment on the Newcastle-Ottawa scale. Three studies were judged to have medium risk of bias and two as high risk of bias for comparability of cohorts. All showed a positive association between the presence of thyroid autoantibodies and premature labors.

Also Negro et al. [22] revealed that euthyroid TPO antibody positive pregnant women had an increased risk of preterm delivery, and treatment with levothyroxin decreased the rate of preterm delivery [22]. Also, investigations in the United States [24] [25], Belgium [16], Pakistan [18], China [26] and Greece [27] showed that TPO antibody positivity increased the risk of preterm delivery.

A large cohort study showed that thyroid autoantibody positivity independent of thyroid dysfunction increased the prenatal mortality rate, but they showed that the prevalence of preterm delivery did not increase in either thyroid autoimmunity or thyroid dysfunction [28].

\section{- Association of thyroid autoantibodies and risk of IUGR}

In the current study there was no difference seen in the IUGR rates compared with control group with the prevalence being $5 \%$ in the study group and also $5 \%$ in the controls.

Leung 1993 [29] and Karakosta 2012 [27], have shown increased rates of low birth weight babies in thyroid autoimmune patient. One cohort study in the United Kingdom in 2009 showed that TPO positive pregnant women had a high risk of low birth weight infants. However, the risk of IUGR in these pregnant women did not increase [28].

Thyroid autoimmunity as a presentation of the immune system deregulation could disorganize the normal immune system adaptation in fetus-maternal unit, and might cause premature labor, leading to low birth weight neonates. Another explanation for this effect is the fact that in chronic lymphocytic thyroiditis, thyroid peroxidase antibody could destroy the thyroid tissue, thereby causing hypothyroidism. Thyroid hormones are essential for the growth and maturation of fetal tissues and could cause intra-uterine growth retardation.

\section{Conclusion}

The presence of anti thyroperoxidase (TPO) antibodies independent of thyroid dysfunction could be correlated to recurrent unexplained abortion and preterm labor. More studies are required to determine whether an intervention is needed to treat thyroid autoantibody positivity during pregnancy.

\section{Declaration of Interest}

The authors report no conflict of interests.

\section{References}

[1] Pereza, N., Ostojić, S., Kapović, M. and Peterlin, B. (2017) Systematic Review and Meta-Analysis of Genetic Association Studies in Idiopathic Recurrent Spontaneous Abortion. Fertility and Sterility, 107, 150-159.e2. 
[2] Lockwood, C.J., Senyei, A.E., Dische, M.R., Casal, D., Shah, K.D., Thung, S.N., et al. (1991) Fetal Fibronectin in Cervical and Vaginal Secretions as a Predictor of Preterm Delivery. The New England Journal of Medicine, 325, 669-674. https://doi.org/10.1056/NEJM199109053251001

[3] Mangham, L.J., Petrou, S., Doyle, L.W., Draper, E.S. and Marlow, N. (2009) The Cost of Preterm Birth throughout Childhood in England and Wales. Pediatrics, 123, e312-e327. https://doi.org/10.1542/peds.2008-1827

[4] Stagnaro-Green, A. and Glinoer, D. (2004) Thyroid Autoimmunity and the Risk of Miscarriage. Best Practice \& Research. Clinical Endocrinology \& Metabolism, 18, 167-181. https://doi.org/10.1016/j.beem.2004.03.007

[5] Batra, C.M. (2013) Fetal and Neonatal Thyrotoxicosis. Indian Journal of Endocrinology and Metabolism, 17, 50-54. https://doi.org/10.4103/2230-8210.119505

[6] Laurberg, P., Bournaud, C., Karmisholt, J. and Orgiazzi, J. (2009) Management of Graves' Hyperthyroidism in Pregnancy: Focus on Both Maternal and Foetal Thyroid Function, and Caution against Surgical Thyroidectomy in Pregnancy. European Journal of Endocrinology, 160, 1-8. https://doi.org/10.1530/EJE-08-0663

[7] Poppe, K., Velkeniers, B. and Glinoer, D. (2008) The Role of Thyroid Autoimmunity in Fertility and Pregnancy. Nature Clinical Practice Endocrinology \& Metabolism, 4, 394-405. https://doi.org/10.1038/ncpendmet0846

[8] Bussen, S. and Steck, T. (1995) Thyroid Autoantibodies in Euthyroid Non-Pregnant Women with Recurrent Spontaneous Abortions. Human Reproduction, 10, 29382940. https://doi.org/10.1093/oxfordjournals.humrep.a135823

[9] Kutteh, W.H., Yetman, D.L., Carr, A.C., Beck, L.A. and Scott Jr., R.T. (1999) Increased Prevalence of Antithyroid Antibodies Identified in Women with Recurrent Pregnancy Loss but Not in Women Undergoing Assisted Reproduction. Fertility and Sterility, 71, 843-848. https://doi.org/10.1016/S0015-0282(99)00091-6

[10] Pratt, D., Novotny, M., Kaberlein, G., Dudkiewicz, A. and Gleicher, N. (1993) Antithyroid Antibodies and the Association with Non-Organ-Specific Antibodies in Recurrent Pregnancy Loss. American Journal of Obstetrics \& Gynecology, 168, 837841. https://doi.org/10.1016/S0002-9378(12)90830-3

[11] Negro, R., Formoso, G., Coppola, L., Presicce, G., Mangieri, T., Pezzarossa, A., et al. (2007) Euthyroid Women with Autoimmune Disease Undergoing Assisted Reproduction Technologies: The Role of Autoimmunity and Thyroid Function. Journal of Endocrinological Investigation, 30, 3-8. https://doi.org/10.1007/BF03347388

[12] Glinoer, D. and Delange, F. (2000) The Potential Repercussions of Maternal, Fetal, and Neonatal Hypothyroxinemia on the Progeny. Thyroid, 10, 871-887.

https://doi.org/10.1089/thy.2000.10.871

[13] Prummel, M.F. and Wiersinga, W.M. (2004) Thyroid Autoimmunity and Miscarriage. European Journal of Endocrinology, 150, 751-755.

https://doi.org/10.1530/eje.0.1500751

[14] Stagnaro-Green, A., Abalovich, M., Alexander, E., Azizi, F., Mestman, J., Negro, R., et al. (2011) Guidelines of the American Thyroid Association for the Diagnosis and Management of Thyroid Disease during Pregnancy and Postpartum. Thyroid, 21, 1081-1125. https://doi.org/10.1089/thy.2011.0087

[15] Stagnaro-Green, A., Roman, S.H., Cobin, R.H., el-Harazy, E., Alvarez-Marfany, M. and Davies, T.F. (1990) Detection of At-Risk Pregnancy by Means of Highly Sensitive Assays for Thyroid Autoantibodies. JAMA, 264, 1422-1425. https://doi.org/10.1001/jama.1990.03450110068029

[16] Glinoer, D., Soto, M.F., Bourdoux, P., Lejeune, B., Delange, F., Lemone, M., et al. (1991) Pregnancy in Patients with Mild Thyroid Abnormalities: Maternal and Neo- 
natal Repercussions. The Journal of Clinical Endocrinology \& Metabolism, 73, 421427. https://doi.org/10.1210/jcem-73-2-421

[17] Lejeune, B., Grun, J.P., de Nayer, P., Servais, G. and Glinoer, D. (1993) Antithyroid Antibodies Underlying Thyroid Abnormalities and Miscarriage or Pregnancy Induced Hypertension. British Journal of Obstetrics and Gynaecology, 100, 669-672. https://doi.org/10.1111/j.1471-0528.1993.tb14236.x

[18] Ghafoor, F., Mansoor, M., Malik, T., Malik, M.S., Khan, A.U., Edwards, R., et al. (2006) Role of Thyroid Peroxidase Antibodies in the Outcome of Pregnancy. Journal of the College of Physicians and Surgeons_Pakistan, 16, 468-471.

[19] Glinoer, D., Riahi, M., Grun, J.P. and Kinthaert, J. (1994) Risk of Subclinical Hypothyroidism in Pregnant Women with Asymptomatic Autoimmune Thyroid Disorders. The Journal of Clinical Endocrinology \& Metabolism, 79, 197-204.

[20] Iijima, T., Tada, H., Hidaka, Y., Mitsuda, N., Murata, Y. and Amino, N. (1997) Effects of Autoantibodies on the Course of Pregnancy and Fetal Growth. Obstetrics \& Gynecology, 90, 364-369.

[21] Haddow, J.E., Cleary-Goldman, J., McClain, M.R., Palomaki, G.E., Neveux, L.M., Lambert-Messerlian, G., et al. (2010) Thyroperoxidase and Thyroglobulin Antibodies in Early Pregnancy and Preterm Delivery. Obstetrics \& Gynecology, 116, 58-62. https://doi.org/10.1097/AOG.0b013e3181e10b30

[22] Negro, R., Formoso, G., Mangieri, T., Pezzarossa, A., Dazzi, D. and Hassan, H. (2006) Levothyroxine Treatment in Euthyroid Pregnant Women with Autoimmune Thyroid Disease: Effects on Obstetrical Complications. The Journal of Clinical Endocrinology \& Metabolism, 91, 2587-2591. https://doi.org/10.1210/jc.2005-1603

[23] Negro, R. (2011) Thyroid Autoimmunity and Pre-Term Delivery: Brief Review and Meta-Analysis. Journal of Endocrinological Investigation, 34, 155-158. https://doi.org/10.1007/BF03347047

[24] Casey, B.M., Dashe, J.S., Wells, C.E., McIntire, D.D., Byrd, W., Leveno, K.J., et al. (2005) Subclinical Hypothyroidism and Pregnancy Outcomes. Obstetrics \& Gynecology, 105, 239-245. https://doi.org/10.1097/01.AOG.0000152345.99421.22

[25] Stagnaro-Green, A. (2009) Maternal Thyroid Disease and Preterm Delivery. The Journal of Clinical Endocrinology \& Metabolism, 94, 21-25. https://doi.org/10.1210/jc.2008-1288

[26] Su, P.Y., Huang, K., Hao, J.H., Xu, Y.Q., Yan, S.Q., Li, T., et al. (2011) Maternal Thyroid Function in the First Twenty Weeks of Pregnancy and Subsequent Fetal and Infant Development: A Prospective Population-Based Cohort Study in China. The Journal of Clinical Endocrinology \& Metabolism, 96, 3234-3241. https://doi.org/10.1210/jc.2011-0274

[27] Karakosta, P., Alegakis, D., Georgiou, V., Roumeliotaki, T., Fthenou, E., Vassilaki, M., et al. (2012) Thyroid Dysfunction and Autoantibodies in Early Pregnancy Are Associated with Increased Risk of Gestational Diabetes and Adverse Birth Outcomes. The Journal of Clinical Endocrinology \& Metabolism, 97, 4464-4472. https://doi.org/10.1210/jc.2012-2540

[28] Mannisto, T., Vaarasmaki, M., Pouta, A., Hartikainen, A.L., Ruokonen, A., Surcel, H.M., et al. (2009) Perinatal Outcome of Children Born to Mothers with Thyroid Dysfunction or Antibodies: A Prospective Population-Based Cohort Study. The Journal of Clinical Endocrinology \& Metabolism, 94, 772-779. https://doi.org/10.1210/jc.2008-1520

[29] Leung, A.S., Millar, L.K., Koonings, P.P., Montoro, M. and Mestman, J.H. (1993) Perinatal Outcome in Hypothyroid Pregnancies. Obstetrics \& Gynecology, 43, 230. https://doi.org/10.1016/0020-7292(93)90343-u 
Submit or recommend next manuscript to SCIRP and we will provide best service for you:

Accepting pre-submission inquiries through Email, Facebook, LinkedIn, Twitter, etc. A wide selection of journals (inclusive of 9 subjects, more than 200 journals)

Providing 24-hour high-quality service

User-friendly online submission system

Fair and swift peer-review system

Efficient typesetting and proofreading procedure

Display of the result of downloads and visits, as well as the number of cited articles Maximum dissemination of your research work

Submit your manuscript at: http://papersubmission.scirp.org/

Or contact ojog@scirp.org 